\title{
CAPÍTULO 34
}

\section{MONITORAÇÃO RADIOLÓGICA DOS EFLUENTES GASOSOS DO REATOR IEA-R1 DO IPEN}

Luiz H. Gabriel, Carlos E. C. Rodrigues, Paulo R. Nogueira, Sandra R. Damatto, Vera L. K. Isiki, Luiz F. L. Teixeira, Marcelo F. Máduar e Marcos M. Alencar

Laboratório de Radiometria Ambiental - Centro de Metrologia das Radiações Instituto de PesquisasEnergéticas e Nucleares

luiz.henrique.gabriel@usp.br

\section{RESUMO}

A operação normal de uma instalação nuclear ou radiativa envolve a liberação de efluentes radioativos líquidos e/ou gasosos. No Instituto de Pesquisas Energéticas e Nucleares (IPEN) existem diversas instalações nucleares e radiativas, desenvolvendo atividades no campo da física nuclear, radioquímica, engenharia nuclear, produção de radioisótopos e radio fármacos, aplicação de técnicas nucleares na indústria entre outras. A Gerência de Radioproteção do IPEN estabeleceu um programa de amostragem dos efluentes radioativos para determinar a quantidade de material radioativo (termo fonte) liberada para o meio ambiente e detectar imediatamente, qualquer liberação não planejada acima dos limites operacionais pré-estabelecidos. O controle radioativo dos efluentes gasosos e do ar atmosférico ambiental do Instituto foi implementado em 1988 e é realizado pelo Laboratório de Radiometria Ambiental - Centro de Metrologia das Radiações. No controle dos efluentes gasosos são analisados semanalmente, por espectrometria 
gama de alta resolução com detector de germânio hiperpuro, filtros de celulose e de carvão das instalações radioativas do IPEN, como o Centro do Reator de Pesquisas IEA-R1 e também o Centro de Aceleradores e Cíclotron e a Diretoria de Radiofarmácia - Prédio I e II. Desde a operação do controle dos efluentes gasosos há trinta anos, mais de 3000 filtros foram analisados e os radionuclídeos determinados na maioria das amostras durante esse período de amostragem no Centro do Reator de Pesquisas IEA-R1 foram ${ }^{131} \mathrm{I}$ e ${ }^{123} \mathrm{I}$. Os resultados obtidos das análises dos filtros do controle dos efluentes gasosos são publicados em relatório de avaliação periódica e disponibilizados internamente via intranet. Todos os resultados obtidos, de 1988 a 2018, confirmam que a liberação de efluentes gasosos radioativos da operação normal das instalações nucleares e radioativas do IPEN está sendo adequadamente controlada e que o impacto radiológico causado por essa liberação é insignificante quando comparado aos limites recomendados pela regulamentação atual da CNEN de 2005.

\section{INTRODUÇ̃̃̃O}

No Instituto de Pesquisas Energéticas e Nucleares (IPEN) há diversas instalações nucleares e radiativas, desenvolvendo atividades no campo da física nuclear, radioquímica, engenharia nuclear, produção de radioisótopos e radiofármacos, aplicação de técnicas nucleares na indústria e radioproteção e monitoração ambiental.

A atividade normal de uma instalação nuclear ou radiativa, assim como qualquer outra atividade humana, apresenta certo risco, pois, em geral, envolve a liberação de efluentes radioativos líquidos e/ou gasosos; uma completa remoção dos radionuclídeos contidos nestes efluentes, antes de serem liberados para o meio ambiente, não é praticamente possível.

A Gerência de Radioproteção da instituição, por meio da Supervisão de Radioproteção de cada instalação estabelece o programa de amostragem dos efluentes radioativos [1] para determinar a quantidade de material radioativo, termo fonte, liberada para o meio ambiente e detectar imediatamente qualquer liberação não planejada acima dos limites operacionais pré- estabelecidos.

O controle de efluentes é, portanto, uma monitoração de caráter preventivo, pois uma vez determinado o termo fonte da instalação e as características do meio ambiente receptor, é possível avaliar a dose de radiação recebida pelos indivíduos do público e, em particular, pelo grupo crítico, antes que o material radioativo seja lançado no meio ambiente. 
Para demonstrar que as doses de radiação proveniente da liberação dos efluentes radioativos permanecem abaixo dos limites estipulados, em um grau de risco aceitável para a população em geral, durante a operação normal das instalações, são realizadas medidas in-loco do nível de radioatividade. Estas medidas são realizadas na forma de um programa de monitoração radiológica ambiental [2,3]. Portanto, o objetivo primário de um programa de monitoração radiológica ambiental é o controle radiológico, um controle de caráter confirmatório, que irá estimar se as suposições feitas no cálculo de dose, a partir do termo fonte, estão corretas.

Os laboratórios do Laboratório de Radiometria Ambiental (LRA) do Centro de Metrologia das Radiações (CMR) foram instituídos a partir dos anos 1980. O LRA estabeleceu e realiza rotineiramente o Programa de Monitoração Radiológica Ambiental do IPEN, desde a sua implementação em 1988, além de realizar a coleta e medida dos efluentes radioativos gasosos do IPEN, onde estão inclusos os gerados pela operação rotineira do reator IEA-R1. Portanto, o objetivo deste trabalho foi apresentar os resultados obtidos da analise dos efluentes gasosos, coletados em filtros de papel e carvão, liberados para o meio ambiente e provenientes da operação do Reator de Pesquisas IEA-R1.

\section{METODOLOGIA}

\subsection{Amostragem e Medida dos Filtros de Papel e Carvão}

Os efluentes radioativos gasosos são coletados por meio da amostragem de arsemanal, utilizando filtros de papel e carvão ativado (Figura la e 1b), coletados na chaminé do reator IEA-R1 (Figura 2).

Os filtros de papel e carvão ativado são analisados por espectrometria gama com detector de germânio hiper puro e eletrônica associada a um analisador multicanal. A análise dos espectros gama foi realizada com o código InterWinner [5]. Nesses filtros, os radionuclídeos ${ }^{123} \mathrm{I}$ e ${ }^{131} \mathrm{I}$ foram determinados a partir do termo fonte anual das instalações do IPEN [6].

A metodologia de medida por espectrometria gama é verificada anualmente no Programa Nacional de Intercomparação (PNI) coordenado pelo IRD-CNEN/ RJ [7], cujas medidas realizadas no LRA apresentam resultados satisfatórios.

Os resultados das análises dos filtros são compilados e avaliados anualmente na forma de um relatório de avaliação das doses efetivas nos grupos críticos da população decorrentes da operação rotineira das instalações do IPEN [8] e de um relatório de avaliação do Programa de Monitoração Radiológica Ambiental do IPEN [9]. 
Figura 1 - Amostragem de ar no reator IEA-R1; amostrador de ar (a); filtros de carvão e papel (b).

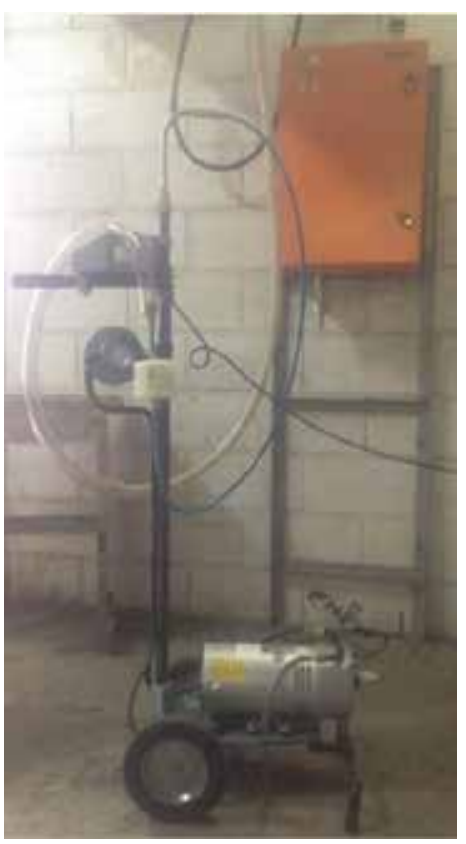

(a)

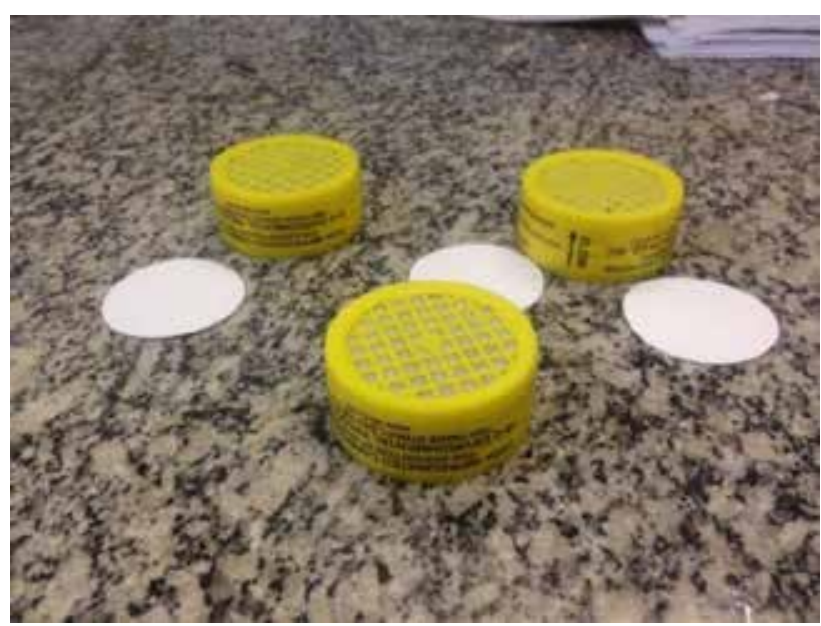

(b)

O impacto radiológico provocado pela operação da instalação nuclear e radiativa funcionando nas dependências do IPEN é avaliado considerando a influência da operaçãonormal na comunidade circunvizinha, isto é, avaliando a dose nos indivíduos do público [10].

\subsection{Estimativa da dose efetiva no grupo crítico no ano de 2018}

A modelagem da dispersão na atmosfera dos efluentes gasosos e aerossóis liberados pelo reator IEA-R1 em operação rotineira foi feita com o uso dos dados meteorológicos locais correspondentes ao máximo período contínuo de operação da torre meteorológica situada no campus do IPEN. No período compreendido entre os anos de 2000 e 2006 predominaram os ventos provenientes do setor SSE, durante 19,94\% do tempo, medidos à altura de $30 \mathrm{~m}$. A média geométrica da velocidade dos ventos deste setor foi de $u a=2,86 \mathrm{~m} / \mathrm{s}[11,12]$. A Figura 3 apresenta uma imagem aérea do campus do IPEN e seu entorno [13]. 
Figura 2 - Mapa descritivo das instalações do IPEN, em destaque o Centro do Reator de Pesquisas [4].

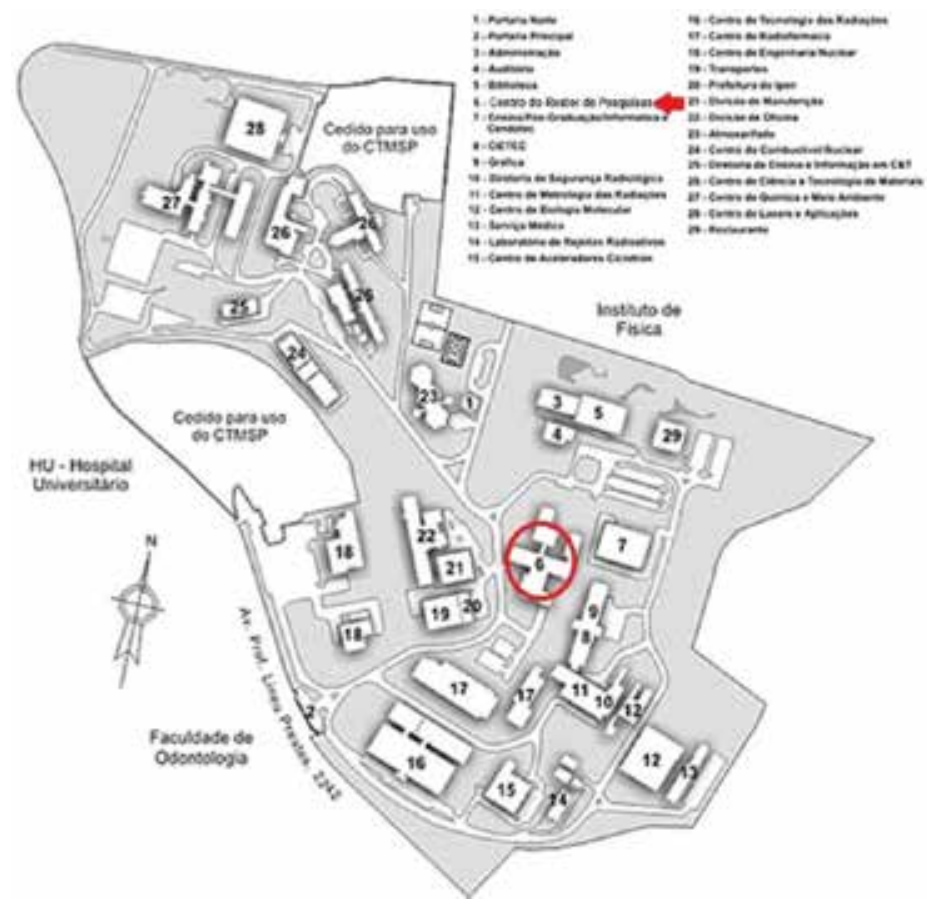

Figura 3 - Imagem aérea do campus do IPEN e seu entorno [13].

\section{Google Maps}

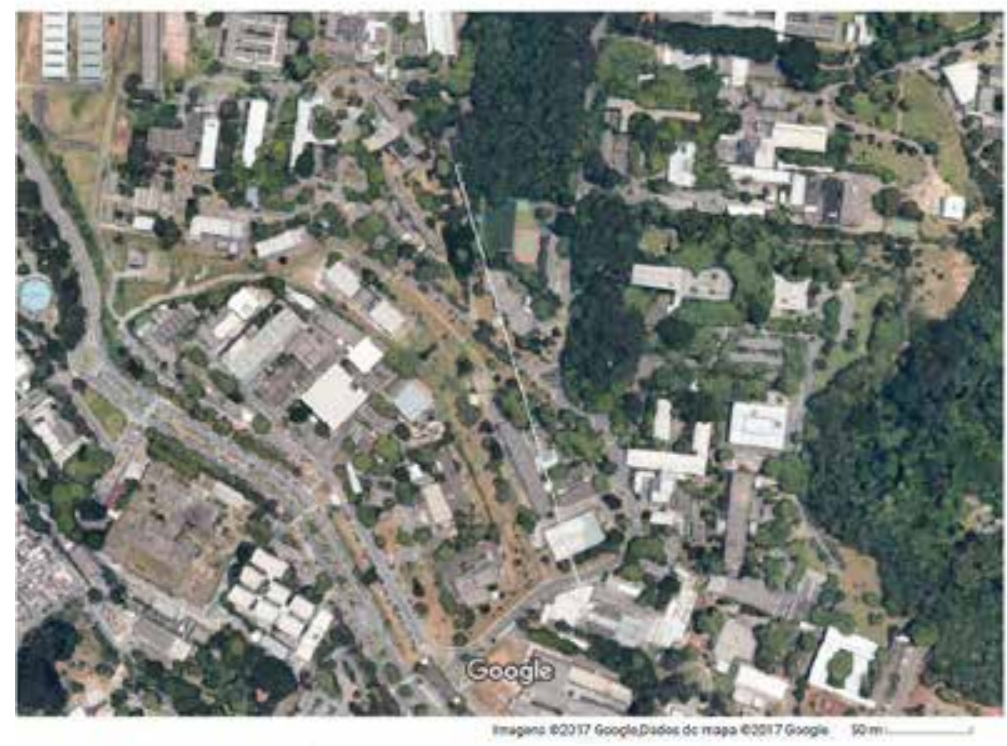

Medir Airtincia

Distancia totst $481.94 \mathrm{~m}(1.57921$ ses) 
O grupo crítico da população para a exposição aos efluentes gasosos e aerossóis foi definido como sendo constituído pelos trabalhadores e frequentadores do Parque Esporte para Todos, que é a área externa ao campus mais próxima às chaminés das instalações do IPEN no setor NNW. A distância mínima do local aos pontos de liberação é de $450 \mathrm{~m}$ lineares.

Para efluentes gasosos e aerossóis, e considerando que não há atividade agrícola na zona de influência das instalações, as vias de exposição do indivíduo à radiação a serem consideradas são:exposição interna pela inalação do material na nuvem radioativa;irradiação externa a partir de depósitos de radionuclídeos no solo;irradiação externa decorrente da imersão do indivíduo na nuvem radioativa [14].

A liberação de efluentes gasosos e aerossóis é feita pela chaminé no edifício do Reator de Pesquisas IEA-R1 e ocorre na zona atmosférica de deslocamento. Nesse caso, recomenda-se [14] o uso do modelo de pluma gaussiana com médias por setor. Os resultados obtidos para as análises dos filtros de papel e carvão dos efluentes gasoso são publicados em um relatório de avaliação periódica, disponibilizado internamente via intranet e encaminhados anualmente ao IBAMA e CNEN.

\section{RESULTADOS E DISCUSSÃO}

Nos trinta anos de operação do PMRA (Programa de Monitoramento Radiológico Ambiental) os resultados das análises têm mostrado que os níveis de dispensa de rejeitos radioativos gasosos, do Reator de Pesquisas IEA-R1, estão dentro do permitido pela norma da CNEN [11]. Para exemplificar os resultados de concentração de atividade dos filtros de papel e carvão provenientes do reator IEA-R1, na Figura 4 são apresentados os resultados de medida de ${ }^{123} \mathrm{I}$ e ${ }^{131} \mathrm{I}$ dos referidos filtros do ano de 2018. A atividade total liberada de ${ }^{131} \mathrm{I}$ para a atmosfera em 2018 foi estimada em 2,7 × 10 5 Bq [6]. Adotando a hipótese conservativa na qual o indivíduo estivesse submetido simultaneamente à exposição decorrente de todas as vias de exposição e todos os radionuclídeos considerados, a dose efetiva no grupo crítico da população decorrente da descarga de efluentes gasosos e aerossóis radioativos pelo reator IEA-R1 foi estimada em 2,2 $\times 10^{-7} \mathrm{mSv}$ durante o ano de 2018. Este valor pode ser considerado insignificante do ponto de vista de proteção radiológica, pois é seis ordens de magnitude inferior ao limite de dose anual máximo admissível para indivíduos do público [11], que é de $1 \mathrm{mSv} / \mathrm{ano}$. 
Figura 4 - Concentração de atividade dos radionuclídeos 123I e 131I, ano de 2018, e correspondentes níveis de dispensa de cada radionuclídeo.

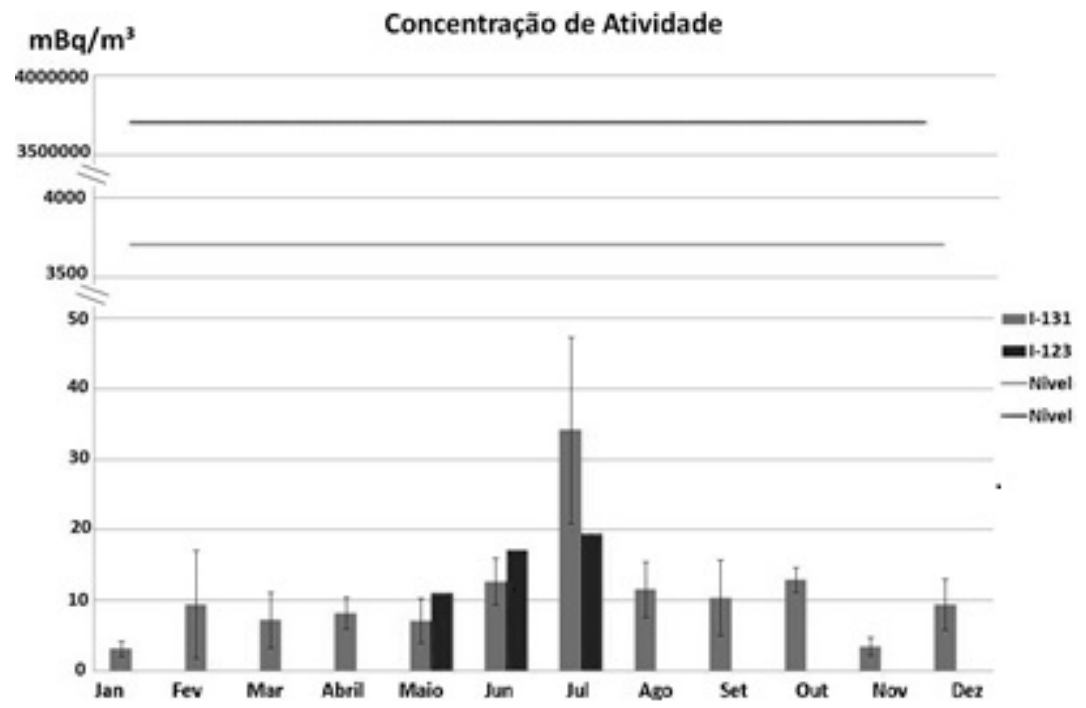

\section{CONCLUSÕES}

Todos os resultados históricos obtidos até o momento, desde a implementação em 1988 do Programa de Monitoração Radiológica Ambiental do IPEN, confirmam que a liberação de efluentes gasosos radioativos da operação normal do reator IEA-R1 do IPEN está sendo adequadamente controlada e o impacto radiológico causado por liberação gasosa de material radioativo é insignificante quando comparado aos limites recomendados pela regulamentação atual da Comissão nacional de Energia Nuclear.

\section{REFERÊNCIAS}

1. PGRP "Plano Geral de Radioproteção das Instalações Nucleares e Radiativas do IPENCNEN/SP". Documentos Ambientais e de Segurança do SGI. LISTA MESTRA DO SGI DAQUALIDADE, MEIO AMBIENTE E SEGURANÇA. Sistema de Gestão Integrada do IPEN. São Paulo, novembro, 2002.

2. PR 3.01/008:2011 POSIÇÃO REGULATÓRIA 3.01/008 "Programa de Monitoração Radiológica Ambiental", da NORMA CNEN - NN - 3.01, aprovada pela resolução CNEN No102, de 22.12.2010, publicada no D.O.U. em 10.05.2011 
3. PR 3.01/009:2011 POSIÇÃO REGULATÓRIA 3.01/009:2011 “Modelo para a Elaboração de Programa de Relatórios de Monitoração Radiológica Ambiental”, da NORMA CNEN - NN- 3.01, aprovada pela resolução CNEN No 102, de 22.12.2010, publicada no D.O.U. em 10.05.2011.

4. Instituto de Pesquisas Energéticas e Nucleares. https://www.ipen.br. Acesso: $5 / 11 / 2019$.

5. Interwinner" 6.0MCA "Emulation, Data Acquisition and Analysis software for Gamma and Alpha Spectroscopy IW-B32 2004.ORTEC”. Oak Ridge, TN, USA. 2004.

6. TERMO-FONTE-G-2018. Termo Fonte do Efluente Radioativo Gasoso das Instalações do ipen - 2018, Documento interno LRA/CMR. São Paulo, 2019.

7. PNI - IRD. "Programa Nacional de Intercomparação de Resultados de Análises de Radionuclídeos em Amostras Ambientais”. Rodadas de abril/1997 a dezembro/2011.

8. DEGCP-"Relatório de avaliação das doses efetivas nos grupos críticos da população decorrentes da operação rotineira das instalações do IPEN no ano de 2010”. 2010.

9. REL-PMRA. "Relatório de avaliação do programa de monitoração radiológica ambiental do IPEN" - 2008.Relatórios. LISTA MESTRA DO SGI DA QUALIDADE, MEIO AMBIENTE E SEGURANÇA. Sistema de Gestão Integrada do ipen. São Paulo, agosto, 2009.

10. IAEA SRS 19 INTERNATIONAL ATOMIC ENERGY AGENCY “Generic models for use inassessing the impact of discharges of radioactive substances to the environment".Vienna, 2001 (Safety Report Series Nr. 19).

11. Norma CNEN NN 8.01. "GERÊNCIA DE REJEITOS RADIOATIVOS DE BAIXO E MÉDIO NÍVEIS DE RADIAÇÃO”, Resolução CNEN 167/14 Abril / 2014.

12. RA-DEGCP-2016. Relatório de avaliação das doses efetivas nos grupos críticos da população decorrentes da operação rotineira das instalações do IPEN - 2016, Documento interno LRA/CMR. São Paulo, 2017.

13. GOOGLE. https://www.google.com.br/maps/@-23.5635355,-46.7355024,1471 $\mathrm{m} /$ data $=$ !3m1!1e3?hl=pt-BR. Acesso em: $1^{\circ}$ jun. 2017.

14. INTERNATIONAL ATOMIC ENERGY AGENCY. Generic models for use in assessing the impact of discharges of radioactive substances to the environment. Vienna: IAEA, 2001. (SafetyReports Series, n. 19.) 